\title{
Genetic and Environmental Causes of Variation in Trait Resilience in Young People
}

\author{
Trine Waaktaar $\cdot$ Svenn Torgersen
}

Received: 23 May 2011 / Accepted: 7 November 2011/Published online: 19 November 2011

(c) The Author(s) 2011. This article is published with open access at Springerlink.com

\begin{abstract}
The aim of this multi-informant twin study was to determine the relative role of genetic and environmental factors in explaining variation in trait resilience in adolescents. Participants were consenting families $(N=2,638$ twins in 1,394 families), from seven national cohorts (age 12-18 years, both sexes) of monozygotic and dizygotic twins reared together. Questionnaire data on the adolescents' Ego-resilience (ER89) was collected from mothers, fathers and twins, and analysed by means of multivariate genetic modelling. Variance in trait resilience was best represented in an ADE common pathways model with sex limitation. Variance in the latent psychometric resilience factor was largely explained by additive genetic factors (77\% in boys, $70 \%$ in girls), with the remaining variance (23 and 30\%) attributable to non-shared environmental factors. Additive genetic sources explained more than 50\% of the informant specific variation in mothers and fathers scores. In twins, additive and non-additive genetic factors together explained $40 \%$ and non-shared environmental factor the remaining $60 \%$ of variation. In the mothers' scores, the additive genetic effect was larger for boys than for girls. The non-additive genetic factor found in the twins' self ratings was larger in boys than in girls. The remaining sex differences in the specific factors were small. Trait resilience is largely genetically determined.
\end{abstract}

Edited by Deborah Finkel

T. Waaktaar $(\bowtie)$

Centre for Child and Adolescent Mental Health, RBUP Eastern and Southern Norway, Oslo, Norway

e-mail: trine.waaktaar@r-bup.no

S. Torgersen

Department of Psychology, Centre for Child and Adolescent

Mental Health, University of Oslo, Oslo, Norway
Estimates based on several informants rather than single informants approaches are recommended.

Keywords Resilience - Adolescents - Twin study · Heritability $\cdot$ Multiple informants

\section{Introduction}

Many studies on human resilience have focused on how contextual factors may act as buffers against stressful life events and adversity (Cicchetti et al. 1993; Cowen et al. 1994; Hurd and Zimmerman 2010; Luthar 1991). However, it has also long been assumed that there must be a genetic component in human resilience against stress and adversity (Rutter 2003). Moderate to strong genetic effects have been reported in twin studies for several normal personality traits and competencies (Ganiban et al. 2008; Kandler et al. 2009; Koenig et al. 2008; Nes et al. 2006; Raevuori et al. 2007; Vernon et al. 2009) as well as in exceptional talents (Haworth et al. 2010; Vinkhuyzen et al. 2009) However, there are very few genetically informative studies on positive psychological personality traits related specifically to the reactivity to events.

Stein et al. (2009) recently reported a higher frequency of the homozygous 'LL' allele of the 5HTTLPR in a group of undergraduate students with high scores on trait resilience as measured by the Connor-Davidson Resilience Scale (CD-RISC) (Connor and Davidson 2003), but the authors duly emphasize the necessity of replication of this result. A Swedish twin study (Hansson et al. 2008) found moderate heritability estimates $\left(\mathrm{h}^{2}\right.$ ranging between .24 and .49), and zero order shared environmental effects, on measures of well-being, negative and positive mental health. The authors related this to individual salutogenic 
factors and indirectly to trait resilience. Boardman et al. (2008) found $\mathrm{h}^{2}=0.52$ for men and $\mathrm{h}^{2}=0.38$ for women in a study of US adult twins, where resilience was indirectly defined as the residual variance in positive mood after adjusting for life stressors. Apart from these studies, we are not aware of other studies that have approached the study of resilience from a behaviour genetic perspective. Thus, the present state of knowledge in this field does not seem to differ much from that described by Shiner and Caspi (2003) almost 10 years ago: 'Resilience researchers have called for increasing focus on the processes underlying resilience (ref.), and personality research should be an important part of future work in this area. It is curious, also, that genetic studies, which are so integral to research on vulnerability associations, have played such a minor role in research on resilience. From an evolutionary perspective genes are equally likely to protect against environmental insult as they are to create vulnerability to disease...' (pp. 20).

The aim of the present study was to study the aetiology of stress resilience by investigating the relative contribution of genetic and environmental causes to the variability of the personality trait of resilience in adolescents. Adolescence was chosen because it is characterized by developmental change in physical as well as social domains. It is also a phase when several mental disorders, among these anxiety, depression, substance abuse and antisocial behaviours, have their first onset (Moffitt et al. 2007; Nolen-Hoeksema et al. 2007; Wittchen 2008), for a review, see (Kessler et al. 2007). Studying resilience as an individual personality buffer against developing mental difficulties through the normal developmental challenges as well as stressful life events of adolescence can lead to a better understanding resilience in humans in general. Knowledge of the genetic and environmental causes behind individual differences in trait resilience may also have important implications for intervention and prevention.

In the study of personal resilience, two different conceptualizations have traditionally been employed. One is the empirically based personality type approach, where a certain personality profile defines the resilient typology. Studies are often based on measures of the Five Factor Model, where a combination of high scores on Agreeableness, Conscientiousness, Extraversion and Openness and low score on neuroticism, has been found to characterize the resilient type (Asendorpf et al. 2001; Asendorpf and van Aken 1999; Barbanelli 2002; Boehm et al. 2002; Costa et al. 2002; DeFruyt et al. 2002; Rammstedt et al. 2004; Robins et al. 1996; Schnabel et al. 2002), see (Torgersen and Vollrath 2006) for a review. However, resilience has also been approached as a theoretically derived personality construct that can be measured dimensionally. Block \& Block (Block 1950; Block 1951) were among the first to explore resilience from this angle, introducing the concept of Ego-resilience as derived from psychoanalytic theory and explored empirically through inverse factor analysis of Q-sort (Block 1978) personality descriptions. A short form of their original scale, the Ego Resilience Scale 89 (ER89) (Block and Kremen 1996) has later been used on various samples, settings and age groups (Bonanno et al. 2011; Cohn et al. 2009; Ong et al. 2006, 2010; Sahdra et al. 2011; Schaubroeck et al. 2011; Sherman et al. 2010). Several other dimensional resilience scales are also available (Connor and Davidson 2003; Friborg et al. 2003; Jew et al. 1999; Oshio and Koneko 2003; Wagnild and Young 1993). Comparisons of the two traditions (Huey and Weisz 1997; Waaktaar and Torgersen 2010) concerning their ability to predict adaptive behaviors and mental difficulties in children and adolescents have concluded in favor of the FFM typology approach. However, as shown by Waaktaar and Torgersen (2010), this advantage was limited to the prediction of mental difficulties. The ER89 resilience scale performed equally well compared to the FFM in explaining variance in adolescents' adaptive functioning. This, and the fact that the resilience scales are often shorter and thus more easily applied in epidemiological studies and community samples than the comprehensive FFM based measurement instruments, constitute sound reasons for employing the dimensional approach when the scope of the study is narrowed to the resilience phenotype and not personality more generally.

A multiple informant survey of trait resilience in seven Norwegian cohorts of monozygotic and dizygotic adolescent twins of both sexes reared together constituted the data that was entered into the multivariate genetic modelling analyses. The primary hypothesis was that trait resilience would be moderately to strongly heritable. In the case where variation in scores across different informants can be attributed to the same common etiological sources, the multi informant design offers an error free estimate of the relative impact of these on the trait in focus. Earlier studies have shown that not all variation between informants will be due to measurement error or rater bias, and that experience based on unique interactions may allow mothers, fathers and adolescents separately to provide substantive additional information about an adolescent's behavior (Bartels et al. 2007; Hoekstra et al. 2008). The inclusion of scores from mothers and fathers in addition to the twins' self ratings in the present study allows for the expression of such valid observer based differences. In cases where the significant rater specific additive genetic component can be ruled out, exploration of alternative systematic rater bias models may be relevant (Hartman et al. 2007). There was not sufficient previous empirical basis for formulating specific hypotheses about differences in heritability between different informants nor between the sexes. 


\section{Methods}

Participants and procedure

Sample

The population consisted of all twin pairs born in Norway between 1988 and 1994. A total of 5,374 twin pairs (10,748 individuals) were registered in the Norwegian Medical Birth Registry in the relevant birth cohorts. Of these, 574 pairs $(11 \%$ of the twin relevant population) had to be excluded from the study due to being deceased or having missing addresses. All remaining twins born in 1988-1994 (aged 12-18 years at the time of entering the study) were invited to participate. Written informed consent was provided from 2,486 families, which constituted $53 \%$ of the invited families. A total of 1,394 families $(56 \%$ of the consenting families, $30 \%$ of the eligible families, and $26 \%$ of the total twin birth cohorts) returned the survey forms. A flowchart of the study attrition is presented in Fig. 1.

Significant differences in educational level between participating mothers and same age women in the general population (sample mothers mean level $=2.6$; population women mean $\left.=2.2, \chi^{2}=3,131.9, \mathrm{df}=12, P<0.000\right)$ as well as between participating fathers and same age men in the general population (sample fathers, mean level $=2.6$; population men, mean level $=2.1, \chi^{2}=505.3, \mathrm{df}=12$, $P<0.000)$ indicated that some selective attrition based on socioeconomic status may have occurred. Educational levels was measured on a scale from 1 to 4 , with 1 signifying basic education only and 4 higher university grade. Data on the general population were based on available tables from Statistics Norway (2007).

\section{Procedure}

The Norwegian Medical Birth Registry provided the names and addresses of all twins and their parents born in Norway in the seven relevant birth cohorts. The eligible families received a letter by post with information about the study and a letter of consent to be returned from parents as well as from the twins. All consenting families then received posted paper-and-pencil inventories to be filled in by the twins and both parents. Approval was received from The Norwegian Data Inspectorate and the Regional Committee for Ethics in Medicine.

Measures

\section{Trait resilience}

Trait resilience was measured by five items from the original 14 items Ego-Resilience scale (ER89) by Block and Kremen (1996). The items were selected on the basis of having demonstrated superior item-to-scale associations through a series of pilot studies on community high school and college students. The following items were included: (1) I enjoy dealing with new and unusual situations; (2) I usually succeed in making a favorable impression on people; (3) I like to do new and different things; (4) My daily life is full of things that keep me interested; (5) I would be willing to describe myself as a pretty strong personality. Twins' self-rating forms and parental forms were equal except from the substitution of ' $I$ ' and 'me' in the twins' forms with 'The twin' and 'his/her' in the parental forms. Items were scored on a five-point scale from 'Not typical' to 'Very typical'. Final scale inter-item reliability Cronbach's alpha across informants ranged from 0.76 to 0.80 .

\section{Zygosity}

The zygosity was determined by means of a questionnaire for the total sample of twins. A part of the questionnaire has earlier been used in one Norwegian twin study (Torgersen 1979), another part in another twin study (Harris
Fig. 1 Flowchart of study attrition

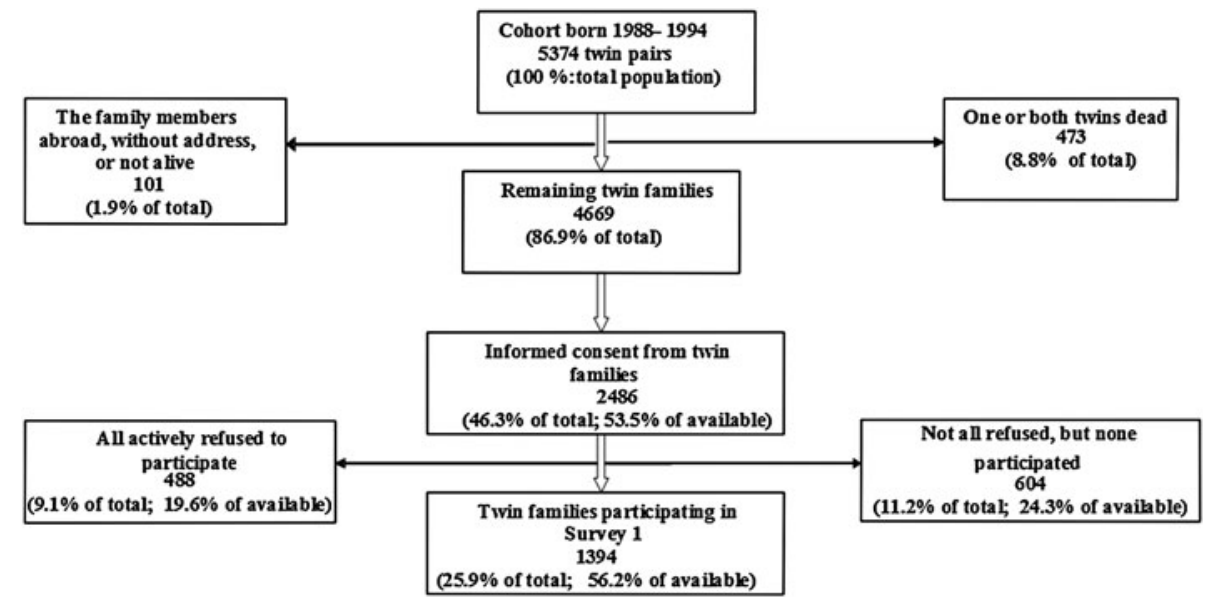


et al. 1995; Tambs et al. 2009). The questionnaire consisted of items about similarity in appearance, how often the twins had been mixed-up with each other, and whether they believed that they were monozygotic or dizygotic. DNA was drawn from a subsample consisting of 204 twin pairs. Eighteen genetic markers were tested, with a probability of misclassification of less than 0.0001 . The non-tested twins were allocated to zygosity group by means of discriminant analysis of the questionnaire data from each twin, mother and father. The misclassification was less than $2 \%$. As twin pairs with equivocal questionnaires were oversampled, the misclassification in the whole sample is expected to be much less.

\section{Data analyses}

\section{General issues}

\section{Data preparation}

Missing variables on item level were imputed with Expectation Maximation (Shafer 1997) (Missing Variables Analysis in SPSS Statistical Package, version 15.01). This imputation method uses other non-missing items from the same scale to impute a value (Expectation) which is then checked as to whether that is the most likely value (Maximization). If not, a more likely value is re-imputed, and this two-step iterative procedure is repeated until the most likely value has been found (SPSS 2007).

To avoid the possibility of spurious inflation of the twin correlations and between informant correlations, imputation was carried out on a within person basis. Thus, mothers' scores on Twin B were not included in estimation of missing items of the mothers' Twin A scores, nor were any other informant's scores. Scales with more than two missing items were set as missing on the whole scale in further analyses. The total proportion of items imputed for any scale was $<2 \%$. Due to significantly negatively skewed distributions (the ratio of skewness/standard error of skewness $>-2$ ) on several of the ER89 scale scores, square root transformations were performed for these variables before entered into the genetic analyses.

Separate linear regression analyses performed on the ER scores for each informant and twin group as dependent showed no significant effects of age. However, there were significant sex effects on the twins' scores. In order to avoid spurious inflation of the common environmental influences, all genetic analyses were performed with the effect of sex on the means structure controlled through the use of residualized scores. Preliminary univariate analyses (within informant) using a correlated factors model $(\mathrm{S} * \mathrm{R} * \mathrm{~S}$ ') (Gaussian decomposition) showed no deviation from the basic assumption of equality of means and variances across twins and across zygosity groups in any of the informants' scores (results of data preparation analyses are available upon request).

Means and standard deviations were calculated using the SPSS Statistical Package, version 15.01. All further data analyses were performed using the open source statistical software package R, version 2.12.0 (R Development Core Team 2008). Specifically, genetic modelling analyses were performed using the OpenMx version 1.0.3 (Boker et al. 2011). OpenMx is an open source software for fitting Structural Equation Models (SEM) to observed data, integrated within the statistical open source statistical program R (R Development Core Team 2008).

\section{Genetic modelling}

The twins reared together design is based on the model assumption that monozygotic (MZ) twins share all (or practically all) their genetic characteristics, while dizygotic (DZ) pairs on the average have $50 \%$ of their segregating genes in common. Thus, any differences in phenotype between $\mathrm{MZ}$ twins have to be caused by unique environmental factors and/or measurement error. Phenotypic MZ correlations above the size of DZ correlations are indications of genetic effects. DZ correlations more than half the size of the MZ correlations must be due to shared environmental factors, while DZ correlations smaller than $50 \%$ of the MZ correlations are indicative of non-additive genetic effects, stemming from either dominance effects (alleles interacting within a particular locus) or epistasis (alleles interacting across different loci). Furthermore, the non-additive genetic and common environmental parameters are fully negatively confounded in this design. This means that any model within this design can contain only one of these two parameters. Non-additive effect models are fit when the MZ correlations exceed the DZ correlations by more than $50 \%$. There is generally little empirical evidence for violations of the two remaining assumptions that must be met for the twin model to be valid: (1) that there is no assortative mating for the phenotype measured; and (2) that MZ and DZ twins are equally exposed to the relevant environmental stimuli for the trait being studied (Bulik et al. 2000; Neale et al. 1998).

Phenotypic correlations do not provide tests of the fit of a specific etiological model, nor of the comparative fit of competing models. Thus, employing a biometrical modelling approach (Neale and Cardon 1992), covariances based on raw data between the twins were fitted to a structural equation model by means of maximum likelihood estimation (FIML). Models were compared using the likelihoodratio $\chi^{2}$ (LRC) statistic and the Akaike information criterion (Akaike 1987), and the sample size adjusted Bayesian 
Information Criterion (BICadj) (Markon and Krueger 2004) were considered during model selection. While the AIC takes into account the overall fit and the parsimony of the model, the BICadj also allows for the comparison of nonnested models. Lower (negative) numbers signify better model fit.

\section{Model fitting}

The genetic models employed in the present study assume that, besides a common view, each informant assesses a rater-specific aspect of the adolescent's behavior (Hewitt et al. 1992). Thus, in addition to contributing to a set of common genetic, common shared environmental and a common-nonshared environmental variance estimates, each informant will constitute a unique source of variation that may meaningfully be partitioned into a unique genetic, a unique shared environmental and a unique non-unshared part (Baker et al. 2007; Bartels et al. 2007). Based on this, three models were tested in the present study: (1) the Cholesky decomposition (this is a descriptive model where all parameters are allowed to vary freely); (2) the independent pathways model and (3) the common pathways model.

In the trivariate Cholesky model, a first set of additive genetic, common environmental (or dominant genetic) and non-shared environmental factors are allowed to influence the scores of all three raters. Then, a second set is allowed to influence the scores of the second and third rater, but not the rater's scores entered first in the model. A last set is allowed only to affect the scores of the informant entered last. Since in the case of modeling multiple informants the order of entry of the variables into the model is insubstantial, a correlated factors solution was employed to secure that the order of the variables would not affect the estimates (Neale et al. 2006; Rijsdijk 2011). The IP model assumes that there is only one common set of additive, shared environmental (or dominant genetic) and nonshared environmental factors influencing variance in all three informants' scores. In addition to the common influences, this model includes informant-specific genetic, shared environmental, and nonshared environmental influences. This tests whether the informants' scores can be expressed by a common set of genetic and environmental causes affecting trait resilience to a different degree, and whether there are etiological aspects of resilience that are uniquely represented by each specific informant.

The common pathways model (CP) is more stringent than the IP model. Within the CP model, genetic and environmental influences upon the different informants scores on trait resilience may be estimated via their effects on a shared underlying latent resilience factor. A particularly interesting aspect of the common pathways model is that the common latent psychometric factor will be unaffected by informant-specific bias and measurement error. The nonshared environmental pathway on the common resilience factor only include environmental influences that in their effect make the twins different from each other. The nonshared environmental pathways on the informantspecific resilience factors will contain measurement error as well as such environmental effects (Neale and Cardon 1992). Thus, given that the common pathways model fits the data, the common factors effects on the latent psychometric resilience factor provide a highly reliable estimate of the effect of the different etiological effects on trait resilience in adolescents.

\section{Results}

\section{Descriptives}

Table 1 shows sample means and standard deviations by gender, zygosity groups and informants.

\section{Correlation structure}

Within person correlations across informant's scores, as well as cross person within informant and cross informant correlations for each zygosity groups (MZ, DZ) and each sex are shown in Table 2. The correlations were generated through ML estimation, and are thus built on the same logic that constitute the basis for the later the twin models.

Table 1 Descriptive data of informants (mothers, fathers and twins), individual ratings by zygosity group

\begin{tabular}{lllll}
\hline Zygosity group & Informant & $N$ & Mean & SD \\
\hline MZ Males & Mother & 423 & 13.75 & 3.05 \\
& Father & 314 & 13.57 & 2.75 \\
& Twins & 413 & 12.99 & 3.00 \\
MZ Females & Mother & 576 & 13.53 & 3.16 \\
& Father & 415 & 13.44 & 3.14 \\
& Twins & 595 & 12.62 & 3.47 \\
DZ Males & Mother & 381 & 14.08 & 2.96 \\
& Father & 288 & 13.58 & 3.16 \\
& Twins & 373 & 13.13 & 3.40 \\
DZ Females & Mother & 456 & 13.60 & 3.20 \\
& Father & 328 & 13.55 & 2.99 \\
& Twins & 477 & 12.51 & 3.27 \\
DOS & Mother & 775 & 13.85 & 3.12 \\
& Father & 581 & 13.38 & 2.96 \\
& Twins & 752 & 13.07 & 3.29 \\
\hline
\end{tabular}

Note: $M Z$ monozygotic, $D Z$ dizygotic 
Table 2 Estimated twin correlations across sex for the different informant scores and the two zygosity groups

\begin{tabular}{|c|c|c|c|c|c|c|c|c|c|c|c|c|c|c|c|}
\hline & & \multicolumn{3}{|c|}{ Within person correlations } & & & \multicolumn{9}{|c|}{$\begin{array}{l}\text { Cross person correlations: within informant (diagonal) and cross informant } \\
\text { (off diagonals) }\end{array}$} \\
\hline & & \multirow[b]{2}{*}{ Mo } & \multirow[b]{2}{*}{$\mathrm{Fa}$} & \multirow[b]{2}{*}{ Tw } & & & \multicolumn{3}{|c|}{ Male pairs } & \multicolumn{3}{|c|}{ Female pairs } & \multicolumn{3}{|c|}{ Opposite sex pairs } \\
\hline & & & & & & & Mo & $\mathrm{Fa}$ & $\mathrm{Tw}$ & Mo & $\mathrm{Fa}$ & $\mathrm{Tw}$ & Mo & $\mathrm{Fa}$ & $\mathrm{Tw}$ \\
\hline \multirow[t]{2}{*}{ Mother } & Males & 1 & & & Mother & MZ & 0.75 & & & 0.55 & & & - & & \\
\hline & Females & 1 & & & & $\mathrm{DZ}$ & 0.29 & & & 0.15 & & & 0.37 & & \\
\hline \multirow[t]{2}{*}{ Father } & Males & 0.47 & 1 & & Father & MZ & 0.40 & 0.73 & & 0.35 & 0.66 & & - & - & \\
\hline & Females & 0.47 & 1 & & & $\mathrm{DZ}$ & 0.07 & 0.17 & & 0.14 & 0.36 & & 0.11 & 0.38 & \\
\hline \multirow[t]{2}{*}{ Twins } & Males & 0.32 & 0.28 & 1 & Twins & MZ & 0.21 & 0.23 & 0.48 & 0.26 & 0.19 & 0.40 & - & - & - \\
\hline & Females & 0.38 & 0.29 & 1 & & $\mathrm{DZ}$ & 0.10 & 0.15 & 0.12 & 0.09 & 0.12 & 0.21 & 0.13 & 0.04 & 0.10 \\
\hline
\end{tabular}

Inspection of the correlation matrix may give a cursory impression of the associations present in the data. Table 2 shows that in all groups MZ scores were higher than DZ scores. Thus, genetic variance was indicated for all informant scores. Most of the MZ twin correlations were more than double the size of the DZ correlations, indicating that the ADE model would be a more adequate model than the ACE model in the subsequent genetic modelling analyses. There seem to be some differences in the size of the MZ/ DZ correlations between same-sex boys and same-sex girls. However, apart from the markedly lower correlations for the twins scores in the opposite sex group, the correlation between same sex and opposite sex DZ twins were generally of equal scale. Thus, any sex-specific effects were not likely to be of large scale. As expected, the cross informant-cross person correlations (off diagonal entries of Table 2) were higher than the within informant-cross person correlations (diagonal entries). The relative MZ/DZ pattern from the cross informant-within person correlations was, however, maintained in the cross informant-cross person correlations. This would be indicative of genetic contributions to associations between informants. The cross informant-within person correlations (left side of table off diagonal correlations) were generally in the range of medium to low, indicating informant specific as well as common effects.

\section{Tests for fixed effects on means structure}

Separate linear regression analyses (results available from first author on request) performed within $\mathrm{R}$ with ER89 scores for each informant and twin group as dependent variables showed no significant effects of age. However, due to significant sex effects on the twins' scores, all genetic ADE models were performed with the effect of sex on the means structure controlled through the use of residualized ER89-scores.
Multivariate model testing

Based on the results from the correlation matrix and preliminary univariate analyses (available from the first author on request), the multivariate full heterogeneity ADE model was chosen as the starting point for a series of subsequent genetic model testing. The results of model are shown in Table 3.

As we can see from Table 3 models I-II, the ADE model gave an acceptable fit compared to the fully saturated model that allowed all variables covariate with all other variables without any constraint to any parameter. Testing multivariate quantitative and qualitative heterogeneity based on a correlated factors approach (Neale et al. 2006) showed no qualitative sex differences in the variance estimates (ref. models II-IV in Table 8). However, there were significant quantitative sex differences in the variance estimates, implying that the same genetic and environmental factors were influencing the informants' scores, but to a different amount in their evaluation of girls and boys (comparison of models IV-V in Table 3).

Table 3 also shows a comparison between the multivariate Independent pathways model and the Common pathways model, both allowing all path estimates to vary freely between the sexes (models VI-VII). Using the multivariate Correlated factors heterogeneity model as the baseline model, the results show the best fit for the Common pathways model. The CP model was chosen as the preferred model for later analyses.

Further model testing was undertaken to simplify the structure of the CP factor model (models VIII-XVI in Table 3). First, we tested a full homogeneity model to see whether all parameters could be equated across sex (model VIII). This model fit the data significantly more poorly compared to the model with parameters estimated freely for males and females. Then, each common factors and specific factors were dropped individually (but simultaneously for both sexes) from the full ADE common 
Table 3 Selected results of multivariate behavior genetic model fitting of the mothers', fathers' and twins' ratings on the ER89 scale

\begin{tabular}{|c|c|c|c|c|c|c|c|c|c|}
\hline No. & Name & $-2 \mathrm{LL}$ & df & AIC & BICadj & $\Delta \mathrm{LL}$ & $\Delta \mathrm{df}$ & $P$ & $\begin{array}{l}\text { Comparison } \\
\text { model }\end{array}$ \\
\hline I. & Saturated (5 zygosity groups) & 40283.05 & 7012 & 26259.05 & 40287.11 & & & & \\
\hline II. & ADE full heterogeneity & 40407.59 & 7102 & 26203.59 & 40407.12 & 124.55 & 90 & 0.01 & I \\
\hline III & ADE nonscalar sex limitation & 40403.54 & 7105 & 26193.54 & 40407.6 & 0.49 & 3 & 0.92 & II \\
\hline IV. & ADE, quantitative, but no qualitative & 40417.43 & 7114 & 26189.43 & 40421.49 & 13.89 & 9 & 0.13 & III \\
\hline V. & ADE full homogeneity & 40460.76 & 7123 & 26214.76 & 40464.82 & 43.33 & 9 & 0 & IV \\
\hline VI. & ADE heterogeneity IndepPathw & 40412.04 & 7105 & 26202.04 & 40416.1 & 8.5 & 0 & 0 & II \\
\hline VII. & ADEade heterogeneity ComPathw & 40417.59 & 7113 & 26191.59 & 40421.65 & 14.05 & 8 & 0.08 & II \\
\hline VIII & ADEade homogeneity ComPathw & 40463.44 & 7128 & 26207.44 & 40467.5 & 45.85 & 15 & 0 & VII \\
\hline IX. & ComPath DEade (drop Ac) & 40470.84 & 7115 & 26240.84 & 40474.91 & 53.26 & 2 & 0 & VII \\
\hline $\mathrm{X}$. & ComPathw AEade (drop Dc) & 40420.35 & 7115 & 26190.35 & 40424.41 & 2.76 & 2 & 0.25 & VII \\
\hline XI. & ComPathw ADade (drop Ec) & 40490.88 & 7115 & 26260.88 & 40494.94 & 73.29 & 2 & 0 & VII \\
\hline XII. & ComPathw ADEde (drop As) & 40446.1 & 7119 & 26208.1 & 40450.17 & 28.52 & 6 & 0 & VII \\
\hline XIII. & ComPathw ADEae (drop Ds) & 40432.14 & 7119 & 26194.14 & 40436.2 & 14.55 & 6 & 0.02 & VII \\
\hline XIV. & ComPathw AEae (drop Dc and Ds) & 40512.99 & 7121 & 26270.99 & 40517.05 & 95.4 & 8 & 0 & VII \\
\hline $\mathbf{X V}$. & ComPathw AEadnse (drop Dc, And n.s. Ds.) & 40420.35 & 7119 & 26182.35 & 40424.41 & 2.76 & 6 & 0.84 & VII \\
\hline
\end{tabular}

Note: Best fitting model marked in bold

pathways heterogeneity model. This strategy resulted in that Common D and specific D could separately be removed without significant drop in fit compared to the full $\mathrm{CP}$ model (models $\mathrm{X}$ and XIII). However, dropping both (model XIV) was rejected. A model dropping the common $\mathrm{D}$ as well as the two non-significant Ds paths (i.e. the specific $d$ in the mothers' and fathers' scores) did not cause any change fit compared model $\mathrm{X}$. Thus, being the most parsimonious model (as judged by the lowest AIC value), Model XV ended up as the preferred model.

Figure 2 a (boys) and b (girls) show the standardized path estimates for all factors in the final model, separate for each sex. Even though a model setting the common factor path estimates equal between sexes was rejected, for both sexes almost three quarters of the variance in the common psychometric Resilience factor $(78 \%$ in boys and $70 \%$ in girls) could be explained by additive genetic factors. The remaining proportion of the variance $(22 \%$ in boys and $30 \%$ in girls) was attributable to non-shared environmental sources. There was no dominant genetic factor explaining variance in the common psychometric factor for any of the sexes

Table 4 shows the standardized variance components in the final model separate for each sex, with the proportion of the total variance that was explained by genetic and environmental factors in each informant's scores.

Looking at the total variance estimates for each informant's scores, we see a somewhat different pattern in the twins' scores compared to that of the mothers' and fathers'. While the parental scores were mainly explained by additive genetic factors (between three-thirds and three quarters of the mothers' and fathers scores) and some remaining nonshared environmental factors, the genetic source of variance in the twins scores were distributed between additive and dominant genetic factors. The strongest dominant genetic effect was found in the twin boys' scores, while i the twin girls' scores, the proportion of dominant genetic effect was small. The twins' self ratings yielded higher non-shared environmental estimates than the estimates built upon mothers and fathers scores. This was most pronounced in girls, where more than half of the variance in the female twins' scores came from non-shared environmental sources.

Furthermore, a very high proportion of the additive genetic variance in the mothers' and twin boys' scores was due to additive variance in the common factor (between 57 and $99 \%$ ), indicative of a rather high degree of agreement between the mother and the twins in the additive genetic aspects of resilience. The fathers' additive genetic variance in both sexes was about half due to variance in the common factor, half due to additive factors specific for the fathers' scores (Table 4). Thus, the additive genetic variance in the fathers' scores were to a larger extent specific to the fathers' perspective. Dominant genetic factors were only represented through factors specific for the twins' scores. The main proportion of the total non-shared environmental factors were due to factors specific for each informant (52-91\%). In interpreting this result one must keep in mind that any measurement error will be allocated to, and cannot be separated from, the effect of specific non-shared environment factor in this model. 
Fig. 2 a ER common pathways standardized estimates, final model for boys. b ER common pathways standardized estimates, final model for girls

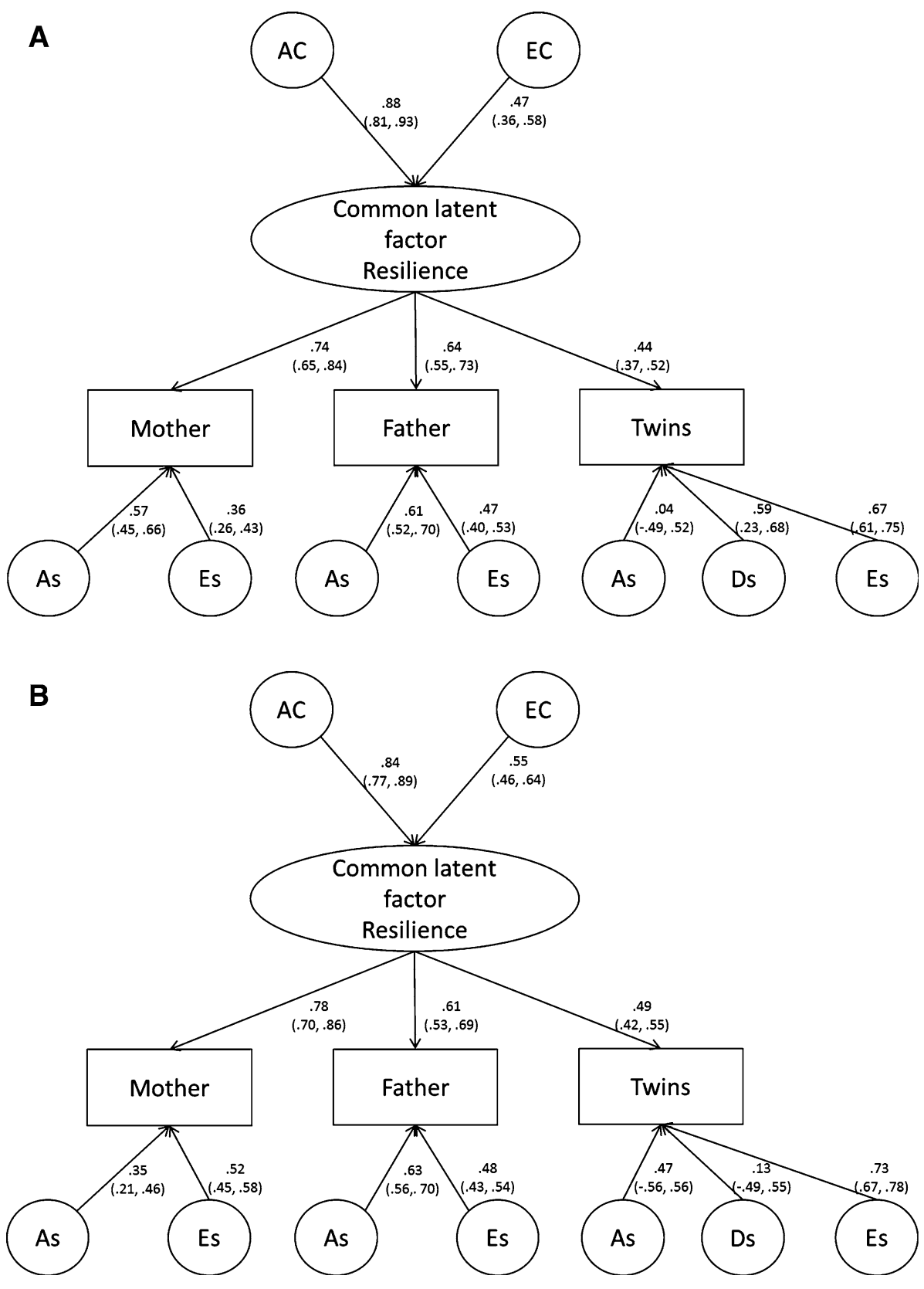

\section{Discussion}

The aim of this multi-informant twin study was to provide reliable estimates of the relative impact of genetic and environmental causes of variation in trait resilience in adolescents.

The results showed that the covariation between the different informants' scores for both sexes could best be modelled by means of a latent psychometric factor, where additive genetic and unique environmental influenced the different informants' scores through the same mechanisms. There were significant sex differences in the size of the estimates in the model. Additive genetic factors explained
$78 \%$ of the variation in the latent psychometric resilience factor in the boys' scores, and 70\% in the girls' scores. The remaining variation in the latent resilience factor was explained by unique environmental factors (23\% in boys, $30 \%$ in girls), while the impact of non-additive genetic factors was negligible.

The heritability estimates of trait resilience found in this study exceeds that from an earlier study by Boardman et al. (2008). One possible explanation is that it may be due to the multivariate design, which is able to produce more reliable estimates than those based on any one single rater. Table 4 shows how the heritability estimates in the present study varied between raters (from $75 \%$ in mothers' ratings of boys 
Table 4 Variance estimates in final model for each sex

\begin{tabular}{|c|c|c|c|c|c|c|c|}
\hline & $\begin{array}{l}\text { Broad-sense } \\
\text { total heritability }\end{array}$ & $\begin{array}{l}\text { Proportion }(\%) \\
\text { due to Ac }\end{array}$ & $\begin{array}{l}\text { Proportion }(\%) \\
\text { due to As }\end{array}$ & $\begin{array}{l}\text { Proportion }(\%) \\
\text { due to Ds }\end{array}$ & $\begin{array}{l}\text { Total } \\
\text { environment }\end{array}$ & $\begin{array}{l}\text { Proportion }(\%) \\
\text { due to } \mathrm{Ec}\end{array}$ & $\begin{array}{l}\text { Proportion }(\%) \\
\text { due to Es }\end{array}$ \\
\hline \multicolumn{8}{|c|}{ Mothers } \\
\hline Boys & 0.75 & 56 & 44 & & 0.24 & 50 & 50 \\
\hline Girls & 0.55 & 78 & 22 & & 0.45 & 40 & 60 \\
\hline \multicolumn{8}{|l|}{ Fathers } \\
\hline Boys & 0.69 & 46 & 54 & & 0.31 & 29 & 71 \\
\hline Girls & 0.66 & 39 & 61 & & 0.34 & 32 & 68 \\
\hline \multicolumn{8}{|l|}{ Twins } \\
\hline Boys & 0.50 & 30 & 00 & 0.70 & 0.49 & 8 & 92 \\
\hline Girls & 0.41 & 41 & 54 & 0.05 & 0.60 & 12 & 88 \\
\hline
\end{tabular}

Note: Ac common additive genetic factor, As informant specific additive genetic factor; $D s$ informant specific dominant genetic factor, Ec common nonshared environmental factor, Es informant specific nonshared environmental factor

to $15 \%$ in boy twins' self ratings). Although genetic factors were also the responsible for the majority of the variance in the fathers' scores, the highest heritability was clearly found in the scores of the mothers. The broad-sense heritability (including the dominant genetic factor) in the twins' scores was around $50 \%$ for boys and $40 \%$ for girls.

All informants' scores loaded substantially on the latent common genetic factor for both sexes, thus there was support for an additive genetic factor that was represented in all informants' ratings of the adolescents' trait resilience. In addition, there was evidence of modest to small genetic effects contributing to differences between each informants' ratings. These effects were most pronounced in the fathers scores, where more than half of the genetic variance was explained by informant specific genetic effects. Rater specific genetic effects contributed to between 1 and $57 \%$ of the total genetic variance in the mothers' and twins' scores.

The main part of the genetic variation in the latent resilience factor came from additive genetic sources, that is, contributions of genes that are independent of each other. Small but significant non-additive genetic effects were specific for the twins' scores only. Non-additive genetic effects have been reported in other personality traits in adolescents (Rebollo et al. 2006; Rettew et al. 2008). It is, however, possible that the significant specific $\mathrm{D}$ found in the twins' self ratings may contain some aspect of negative contrast or competition effects, indicating that the scores of one twin influence the scores of the other twin in the opposite direction (Simonoff et al. 1998). Sibling competition effects act to deflate both MZ and DZ variances, but MZ variances to a higher extent. This also affects covariances, resulting in MZ phenotypic correlations much larger than MZ correlations, thus imitating a dominance effect. Such systematic within informant cross twin rater bias effects are generally hard to explore in the classic twin design due to statistical power issues (Rietveld et al. 2003).
The results of the present study showed that just about one quarter of the total variation in trait resilience was attributable to environmental factors. With no indication of any shared environmental effects in the present data (based on inspection of the correlation structure $\left(r_{\mathrm{DZ}}<1 / 2 r_{\mathrm{MZ}}\right)$ ), all environmental variation in the latent trait resilience must have originated from sources that were not shared between the twins within the same family (the error-free common $\mathrm{E}$ in the model). This is in accordance with what is generally found for most complex human traits (Plomin et al. 2001). Earlier longitudinal studies have pointed to factors within the community, such as friends, school, leisure time and neighbourhood as predictors of better developmental outcomes in the face of stress and adversity (Werner 2000). Several resilience enhancing factors within the family environment have also been suggested, such as intra-familial social support and low marital conflict (Pinkerton and Dolan 2007; Rutter 1999). However, among such potential influences within the family, only those that in effect would make twins within the same family different from one another on trait resilience could be of significance.

There were significant sex differences in the size of the standardized estimates of the common factor model of trait resilience in this study. The estimates of the boys additive genetic effects on the maternal scores were larger, while the nonshared environmental estimates were smaller than the same estimates for the girls. The dominant genetic effect found in the twins' scores was larger for boys than for girls. The differences between the sexes for the remaining informant specific estimates were very small.

\section{Limitations}

The following limitations should be kept in mind when evaluating the results of this study. 
The twins reared together design generally yields common environmental estimates that are lower than those reported in adoption studies (Buchanan et al. 2009).

A comparison between level of education in the participating families compared to age equivalent levels for women and men within the total population give reason to believe that there may be selection bias in the participating families based on socioeconomic indicators. Earlier genetically informative studies have yielded differential heritability estimates across socioeconomic groups (South and Krueger 2011; Tuvblad et al. 2006) as well as in groups with different exposure to various stressful live events (Distel et al. 2011). Unfortunately, limited statistical power impeded the testing of additional moderators beyond this sex limitation model.

Measurement invariance may constitute a challenge in studies where different groups are being compared on measures of complex traits. In fact, the significant differences in latent factor loadings between informants and across sex in the present study may be seen as forms of measurement non-invariance in how trait resilience is being perceived in different groups. As noted by Neale et al. (2005), measurement non-invariance on item level between zygosity groups may impact the estimates in studies based on sum scores. This type of bias would be most pronounced in the case of binary items, and the direction of the bias on the variance estimates will depend on which of the MZ or DZ scores are the best indicators of the latent trait in question. Although preliminary exploratory factor analyses (PCA) in the present study showed preference for a one factor solution for all zygosity groups and factor loadings of each item typically ranging between 0.65 and 0.80 , only a full multivariate simultaneous analysis of measurement model and variance decomposition analytic approach would provide an effective handling of the measurement invariance issue. This kind of analyses have recently contributed informatively in the search for the causal structure between diagnostic criteria within and between DSM diagnostic categories (Torgersen et al. 2008). Further, a comparison between the sum score approach and a combined variance decomposition/item response theory (IRT) measurement model approach (van den Berg et al. 2007) on attention problems resulted in markedly higher heritability estimates with the latter. However, the sum scores approach employed in the present study yielded very high heritability estimates, and analyses at an even more increased level of precision would be premature in this early phase of the study of the resilience phenotype.

\section{Conclusion}

Resilience in adolescents as measured by three informants (mothers, fathers and the twins' self ratings) was best conceptualized as a common latent factor, with additional genetic, shared environmental factors as well as non-shared environmental factors that were specific for each informants' scores. There were significant sex differences in the sizes of the standardized estimates within the model. In the mothers' scores, the genetic factor was larger and the nonshared environmental smaller in the boys, whereas the opposite pattern was representative for the girls. Resilience as a latent personality trait was highly genetically determined for both sexes, with additive genetics effects explaining nearly three quarters of the variance. There was no indication of any common environmental factor in trait resilience, and non-shared environmental factors had a moderate to low effect. There were significant informant specific contributions to the additive genetic effect in all three informants' scores, indicating that a multiple rater approach is necessary in order to reach a more complete understanding of the etiological basis of the phenomenon.

Open Access This article is distributed under the terms of the Creative Commons Attribution Noncommercial License which permits any noncommercial use, distribution, and reproduction in any medium, provided the original author(s) and source are credited.

\section{References}

Akaike H (1987) Factor analysis and AIC. Psychometrika 52(3):317-332

Asendorpf JB, van Aken MAG (1999) Resilient, overcontrolled, and under controlled personality prototypes in childhood: replicability, predictive power, and the trait-type issue. J Pers Soc Psychol 74(6):1531-1544

Asendorpf JB, Borkernau P, Ostendorf F, van Aken MAG (2001) Carving personality descriptions at its joints: confirmation of three replicable personality prototypes for both children and adults. Eur J Pers 15:169-198

Baker LA, Jacobson KC, Raine A, Lozano DI, Bezdjian S (2007) Genetic and environmental bases of childhood antisocial behavior: a multi-informant twin study. J Abnorm Psychol $116(2): 219-235$

Barbanelli C (2002) Evaluating cluster analysis solutions: an application to the Italian NEO personality inventory. Eur J Pers 16(SI):S43-S55

Bartels M, Boomsma DI, Hudziak JJ, Van Beijsterveldt TCEM, Van den Oord EJCG (2007) Twins and the study of rater (Dis)agreement. Psychol Methods 12(4):451-466

Block J (1950) An experimental investigation of the construct of egocontrol. In. Stanford University, Stanford

Block JH (1951) An experimental study of topological representation of ego structure. In. Stanford University, Stanford

Block J (1978) The Q-sort method in personality assessment and psychiatric research. Consulting Psychologists Press, Palo Alto

Block J, Kremen AM (1996) IQ and ego-resiliency: conceptual and empirical connections and separateness. J Pers Soc Psychol 70(2):349-361

Boardman JD, Blalock CL, Button TM (2008) Sex differences in the heritability of resilience. Twin Res Human Genet Off J Int Soc Twin Stud 11(1):12-27 
Boehm B, Asendorph JB, Avia MD (2002) Replicable types and subtypes of personality: Spanish NEO-PI samples. Eur J Pers $16(\mathrm{SI}): 25-41$

Boker S, Neale M, Maes H, Wilde M, Spiegel M, Brick T, Spies J, Estabrook R, Kenny S, Bates T, Mehta P, Fox J (2011) OpenMx: an open source extended structural equation modeling framework. Psychometrika 76(2):306-317

Bonanno GA, Pat-Horenczyk R, Noll J (2011) Coping flexibility and trauma: the Perceived Ability to Cope with Trauma (PACT) scale. Psychological trauma. Theory, Res, Pract, Policy 3(2):117-129

Buchanan JP, McGue M, Keyes M, Iacono WG (2009) Are there shared environmental influences on adolescent behavior? evidence from a study of adoptive siblings. Behav Genet 39(5): $532-540$

Bulik CM, Sullivan PF, Wade TD, Kendler KS (2000) Twin studies of eating disorders: a review. Int J Eat Disord 27(1):1-20

Cicchetti D, Rogosch FA, Lynch M, Holt K (1993) Resilience in maltreated children: processes leading to adaptive outcome. Dev Psychopathol 5:629-647

Cohn MA, Fredrickson BL, Brown SL, Mikels JA, Conway AM (2009) Happiness unpacked: positive emotions increase life satisfaction by building resilience. Emotion 9(3):361-368

Connor CM, Davidson JRT (2003) Development of a new resilience scale: the Connor-Davidson Resilience Scale (CD-RISC). Depress Anxiety 18(2):76-82

Costa PT, Herbst JH, McCrae RR, Samuels J, Ozer DJ (2002) The replicability and utility of three personality types. Eur J Pers 16:73-87

Cowen EL, Wyman PA, Work WC, Iker MR (1994) A preventive intervention for enhancing resilience among highly stressed urban children. J Prim Prev 15(3):247-260

DeFruyt F, Mervielde I, Van Leeuwen K (2002) The consistency of personality type classification across samples and five-factor measures. Eur J Pers 16(SI):57-72

Distel M, Middeldorp C, Trull T, Derom C, Willemsen G, Boomsma D (2011) Life events and borderline personality features: the influence of gene-environment interaction and gene-environment correlation. Psychol Med 41(4):849-860

Friborg O, Hjemdal O, Rosenvinge JH, Martinussen M (2003) A new rating scale for adult resilience: what are the central protective resources behind healthy adjustment? Int $\mathrm{J}$ Methods Psychiatr Res 12(2):65-76

Ganiban JM, Saudino KJ, Ulbricht J, Neiderhiser JM, Reiss D (2008) Stability and change in temperament during adolescence. J Pers Soc Psychol 95(1):222-236

Hansson K, Cederblad M, Lichtenstein P, Reiss D, Pedersen N, Belderhiser J, Elthammar O (2008) Individual resiliency factors from a genetic perspective: results from a twin study. Fam Process 47(4):537-551

Harris JR, Tambs K, Magnus P (1995) Sex-specific effects for body mass index in the new Norwegian twin panel. Genet Epidemiol 12(3):251-265

Hartman CA, Rhee SH, Willcutt EG, Pennington BF (2007) Modeling rater disagreement for ADHD: are parents or teachers biased? J Abnorm Child Psychol 35(4):536-542

Haworth CM, Wright MJ, Luciano M, Martin NG, de Geus EJ, van Beijsterveldt CE, Bartels M, Posthuma D, Boomsma DI, Davis OS, Kovas Y, Corley RP, Defries JC, Hewitt JK, Olson RK, Rhea SA, Wadsworth SJ, Iacono WG, McGue M, Thompson LA, Hart SA, Petrill SA, Lubinski D, Plomin R (2010) The heritability of general cognitive ability increases linearly from childhood to young adulthood. Mol Psychiatry 15(11):11121120

Hewitt JK, Silberg JL, Neale MC, Eaves LJ, Erickson M (1992) The analysis of parental ratings of children's behavior using lisrel. Behav Genet 22(3):293-317
Hoekstra RA, Bartels M, Hudziak JJ, Van Beijsterveldt TCEM, Boomsma DI (2008) Genetic and environmental influences on the stability of withdrawn behavior in children: a longitudinal, multi-informant twin study. Behav Genet 38(5):447-461

Huey SJ Jr, Weisz JR (1997) Ego control, ego resiliency, and the fivefactor model as predictors of behavioral and emotional problems in clinic-referred children and adolescents. J Abnorm Psychol 106(3):404-415

Hurd NM, Zimmerman MA (2010) Natural mentoring relationships among adolescent mothers: a study of resilience. J Res Adolesc 20(3):789-809

Jew CL, Green KE, Kroger J (1999) Development and validation of a measure of resiliency. Measurement and evaluation in counseling and development 3275-3289

Kandler C, Riemann R, Kampfe N (2009) Genetic and environmental mediation between measures of personality and family environment in twins reared together. Behav Genet 39(1):24-35

Kessler RC, Amminger GP, Aguilar-Gaxiola S, Alonso J, Lee S, Ustun TB (2007) Age of onset of mental disorders: a review of recent literature. Curr Opin Psychiatry 20(4):359-364

Koenig LB, McGue M, Iacono WG (2008) Stability and change in religiousness during emerging adulthood. Dev Psychol 44(2): $532-543$

Luthar SS (1991) Vulnerability and resilience: a study of high-risk adolescents. Child Dev 62(3):600-616

Markon K, Krueger RF (2004) An empirical comparison of information-theoretic selection criteria for multivariate behavior genetic models. Behav Genet 34(6):593-609

Moffitt TE, Harrington H, Caspi A, Kim-Cohen J, Goldberg D, Gregory AM, Poulton R (2007) Depression and generalized anxiety disorder-Cumulative and sequential comorbidity in a birth cohort followed prospectively to age 32 years. Arch Gen Psychiatry 64(6):651-660

Neale MC, Cardon LR (1992) Methodology for genetic studies of twins and families. Kluwer Academics, Dordrecht

Neale MC, Kendler KS, Hewitt JK, Silberg JL, Foley DL, Meyer JM (1998) Assortative mating for major psychiatric diagnoses in two population-based samples. Psychol Med 28(6):1389-1401

Neale MC, Lubke G, Aggen SH, Dolan CV (2005) Problems with using sum scores for estimating variance components: contamination and measurement noninvariance. Twin Res Hum Genet 8(6):553-568

Neale MC, Roysamb E, Jacobson K (2006) Multivariate genetic analysis of sex limitation and G x E interaction. Twin Res Hum Genet 9(4):481-489

Nes RB, Roysamb E, Tambs K, Harris JR, Reichborn-Kjennerud T (2006) Subjective well-being: genetic and environmental contributions to stability and change. Psychol Med 36(7):1033-1042

Nolen-Hoeksema S, Stice E, Wade E, Bohon C (2007) Reciprocal relations between rumination and bulimic, substance abuse, and depressive symptoms in female adolescents. J Abnorm Psychol 116(1):198-207

Ong AD, Bergeman C, Bisconti TL, Wallace KA (2006) Psychological resilience, positive emotions, and successful adaptation to stress in later life. J Pers Soc Psychol 91(4):730-749

Ong AD, Zautra AJ, Reid MC (2010) Psychological resilience predicts decreases in pain catastrophizing through positive emotions. Psychol Aging 25(3):516-523

Oshio A, Koneko H (2003) Construct validity of the adolescent resilience scale. Psychol Rep 93((3 Pt 2)):1217-1222

Pinkerton J, Dolan P (2007) Family support, social capital, resilience and adolescent coping. Child \& family social work special issue: working with troubled adolescent 12(3):219-228

Plomin R, Asbury K, Dunn J (2001) Why are children in the same family so different? Nonshared environment a decade later. Can J Psychiatry 46(3):225-233 
R Development Core Team (2008) R: a language and environment for statistical computing. R Foundation for Statistical Computing, Vienna, Austria. ISBN 3-900051-07-0, URL: http://www. R-project.org.

Raevuori A, Dick DM, Keski-Rahkonen A, Pulkkinen L, Rose RJ, Rissanen A, Kaprio J, Viken RJ, Silventoinen K (2007) Genetic and environmental factors affecting self-esteem from age 14 to 17: a longitudinal study of Finnish twins. Psychol Med 37(11):1625-1633

Rammstedt B, Riemann R, Angleitner A, Borkemann P (2004) Resilients, overcontrollers, and undercontrollers: The replicability of the three personality prototypes across informants. Eur $\mathbf{J}$ Pers 18:1-14

Rebollo IM, Boomsma DI (2006) Genetic and environmental influences on type A behavior pattern: evidence from twins and their parents in the Netherlands twin register. Psychosom Med 68(3):437-442

Rettew DC, Rebollo-Mesa I, Hudziak JJ, Willemsen G, Boomsma DI (2008) Non-additive and additive genetic effects on extraversion in 3,314 Dutch adolescent twins and their parents. Behav Genet 38(3):223-233

Rietveld MJ, Posthuma D, Dolan CV, Boomsma DI (2003) ADHD: sibling interaction or dominance: an evaluation of statistical power. Behav Genet 33(3):247-255

Rijsdijk F (2011) MODEL: MV quantitative \& qualitative sex-dif Sex-Limitation script (ACE Correlated Factors model). In. http:// openmx.psyc.virginia.edu/sites/default/files/MVcor3var_\%20IP_ CP_OpenMx.R

Robins RW, John OP, Caspi A, Moffitt TE, Stouthamber-Loeber M (1996) Resilient, overcontrolled, and undercontrolled boys: three replicable personality types. J Pers Soc Psychol 70(1):157-171

Rutter M (1999) Resilience concepts and findings: implications for family therapy. J Fam Ther 21(2):119-144

Rutter M (2003) Genetic influences on risk and protection: implications for understanding resilience. In: Luthar SS (ed) Resilience and vulnerability: adaptation in the context of childhood adversities. Cambridge University, Cambridge

Sahdra BK, MacLean KA, Ferrer E, Shaver PR, Rosenberg EL, Jacobs TL, Zanesco AP, King BG, Aichele SR, Bridwell DA, Mangun GR, Lavy S, Wallace B, Alan SaronCD (2011) Enhanced response inhibition during intensive meditation training predicts improvements in self-reported adaptive socioemotional functioning. Emotion 11(2):299-312

Schaubroeck JM, Riolli LT, Peng AC, Spain ES (2011) Resilience to traumatic exposure among soldiers deployed in combat. J Occup Health Psychol 16(1):18-37

Schnabel K, Asendorph JB, Ostendorf F (2002) Replicable types and subtypes of personality: German NEO-PI-R versus NEO-FFI. Eur J Pers 16(SI):7-24

Shafer JL (1997) Analysis of incomplete multivariate data. Chapman \& Hall, London

Sherman RA, Nave CS, Funder DC (2010) Situational similarity and personality predict behavioral consistency. J Pers Soc Psychol 99(2):330-343

Shiner R, Caspi A (2003) Personality differences in childhood and adolescence: measurement development, and consequences. J Child Psychol Psychiatry 44(1):2-32
Simonoff E, Pickles A, Hervas A, Silberg JL, Rutter M, Eaves L (1998) Genetic influences on childhood hyperactivity: contrast effects imply parental rating bias, not sibling interaction. Psychol Med 28(4):825-837

South S, Krueger R (2011) Genetic and environmental influences on internalizing psychopathology vary as a function of economic status. Psychol Med 41(1):107-117

SPSS (2007) SPSS missing value analysis. In. SPSS Inc, pp

Statistics Norway (2007) Utdanningsnivå i befolkningen. Personer 16 år og over, etter høyeste utdanningsnivå(NUS2000), kjønn og bostedsfylke. 2006. In: Statistics Norway (ed) Utdanningsnivå i befolkningen, pp

Stein MB, Campbell-Sills L, Gelernter J (2009) Genetic variation in 5HTTLPR is associated with emotional resilience. Am J Med Genet 150B(7):900-906

Tambs K, Ronning T, Prescott CA, Kendler KS, Reichborn-Kjennerud T, Torgersen S, Harris JR (2009) The Norwegian institute og public health twin study of mental health: examining recruitment and attrition bias. Twin Res Hum Genet 12(2):10

Torgersen S (1979) The determination of twin zygosity by means of a mailed questionnaire. Acta Genet Med Gemellol 28(3):225-236

Torgersen S, Vollrath M (2006) Personality types, personality traits, and risky health behavior. In: Vollrath $M$ (ed) Handbook of personality and health. Wiley, Chichester, pp 215-233

Torgersen S, Czajkowski N, Jacobson K, Reichborn-Kjennerud T, Roysamb E, Neale MC, Kendler KS (2008) Dimensional representations of DSM-IV cluster B personality disorders in a population-based sample of Norwegian twins: a multivariate study. Psychol Med 38(11):1617-1625

Tuvblad C, Grann M, Lichtenstein P (2006) Heritability for adolescent antisocial behavior differs with socioeconomic status: gene-environment interaction. J Child Psychol Psychiatry 47(7):734-743

van den Berg SM, Glas CA, Boomsma DI (2007) Variance decomposition using an IRT measurement model. Behav Genet 37(4):604-616

Vernon PA, Villani VC, Schermer JA, Kirilovic S, Martin RA, Petrides KV, Spector TD, Cherkas LF (2009) Genetic and environmental correlations between trait emotional intelligence and humor styles. J Ind Diff 30(3):130-137

Vinkhuyzen AAE, van der Sluis S, Posthuma D, Boomsma DI (2009) The heritability of aptitude and exceptional talent across different domains in adolescents and young adults. Behav Genet 39(4):380-392

Waaktaar T, Torgersen S (2010) How resilient are resilience scales? The Big Five scales outperform resilience scales in predicting adjustment in adolescents. Scand J Psychol 51(2):157-163

Wagnild GM, Young HM (1993) Development and psychometric evaluation of the resilience scale. J Nurs Meas 1(2):165-178

Werner EE (2000) Protective factors and individual resilience. In: Shonkoff JP, Meisels SJ (eds) Handbook of early childhood intervention. Cambridge University Press, Cambridge, pp 115-132

Wittchen H, U, Behrendt S, Hofler M, Perkonigg A, Lieb R, Buhringer G, Beesdo K (2008) What are the high risk periods for incident substance use and transitions to abuse and dependence? Implications for early intervention and prevention. Int J Methods Psychiatr Res June 17 Supplement 1S16-S29 